\title{
Analysis of Dynamic Parameters of Observation Towers in Latvia
}

\author{
Liga Gaile \\ Riga Technical University, Department of Structural Analysis. Address: Azenes Street 16, \\ Riga, LV-1048, Latvia.
}

\begin{abstract}
The purpose of this research is to experimentally identify the performance of most of the light-weight observation towers open for public in Latvia. It analyzes the structure of towers, technical condition, dynamic parameters and dynamic response to human movement along the tower height. During the experiment there were measured and recorded the vibration accelerations of 18 observation towers' upper platform. Further dynamic parameters were extracted using the spectral analysis. There was performed the sensitivity analysis to establish parameters that most influences the dynamic response amplitudes due to human movement. All experimentally obtained fundamental frequencies of the inspected towers are in the typical range of human walking frequencies. It is found that the main parameter that denotes the response level (acceleration amplitude) of the tower due to human movement is a tower self-weight.
\end{abstract}

Keywords - acceleration, frequency, human induced vibrations, observation tower.

\section{INTRODUCTION}

Historically the free standing towers primarily were used by military to provide a good observation of the surrounding area. The era of observation towers as a sightseeing symbol probably started in Paris during the 1889 with the Eiffel rise at the World's Fair. Observation towers located in cities usually are tall structures and serve as an architectural symbol but towers located in the countryside are designed to allow viewers an unobstructed view of the landscape and tend to have a design mostly driven by economic aspects.

Latvia has around 20 light-weight observation towers accessible for general public with height more than $20 \mathrm{~m}$ (Fig. 1). Mostly they are located in countryside of Latgale and Kurzeme region. Almost half of them are responsibility of the state company JSC "Latvia's State Forests" that continuously develops environmental infrastructure objects. As an example serves recently opened for public (October, 2012) $28,5 \mathrm{~m}$ high timber observation tower "Ančupānu skatu tornis" near Rezekne city. Although construction of such towers is rather expensive it is a great way to increase tourist flow to the area otherwise not very popular.

Most of the towers in Latvia have set rules to limit the number of visitors from 5 to 10 people however this limit is not based on any research information and construction is purely based on the previous experience. In 2010 a light-weight eccentric steel structure observation tower was opened for public in Jurmala and most of the visitors experience vibration amplitudes causing uncomfortable feeling. This structure highlights the lack of understanding and inadequate design information of the building codes, regarding the slender tower dynamic response to human induced loads [1]. It demonstrates that in areas with low seismicity and relatively low wind loads the human induced dynamic loads could be determinative in a slender and light-weight observation tower design because it is important to meet acceptable comfort level for tower visitors.
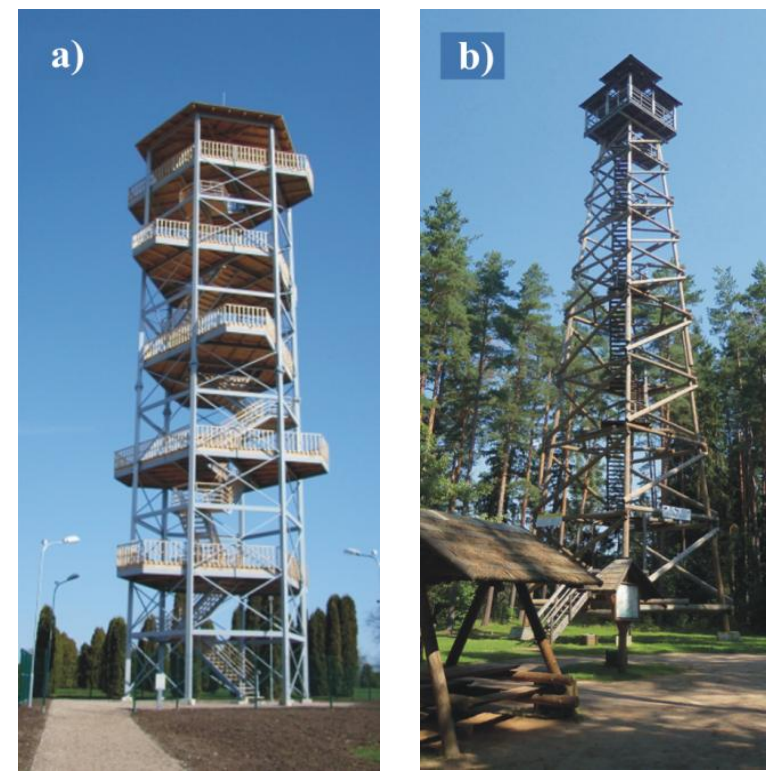

Fig. 1. Observation towers: a) steel, b) timber

From the extensive experimental and numerical researches in last decade regarding the light-weight footbridge vibrations induced by human dynamic loads it is known that slightly damped bridges become susceptible to vibrations when structures natural frequencies are in the range of human step frequencies [2]-[5]. In the case of bridge pedestrian density greatly influences the step frequency [6]. The mean step frequency for the low density (0.2-0.5 Persons $/ \mathrm{m} 2$ ) pedestrian stream is $1.8-1.9 \mathrm{~Hz}$ according to [6].

In the case of stairs that is essential component of any lattice observation tower there is a wide variation of walking speeds and therefore the wide variation of step frequencies can be found in literature. The study 
[7] presents the measured walking speeds of 485 individuals on "the long stairs" during the event Expo 2000 in Hannover. It was found that in case of small or no visible influence among individuals the mean footfall frequency is $1.416 \mathrm{~Hz}$ with standard deviation of $0.277 \mathrm{~Hz}$. The observed minimum frequency was $0.48 \mathrm{~Hz}$ and maximum (corresponds to running) was $4.25 \mathrm{~Hz}$.

To assess the existing observation towers dynamic performance in this study there were experimentally measured and recorded data of 18 observation tower's top platform vibration acceleration under an operational conditions. There were obtained the natural frequencies exited by human movement up and down along the towers' height, dynamic response levels (acceleration amplitudes) and damping ratios for the most of observation towers in Latvia. Additionally there were theoretically analyzed parameters that most influences the response level (vibration acceleration and displacement amplitudes) under the human induced typical walking load.

\section{MATERIALS AND METHODS}

\section{A. Experimental programme}

During the experiments there were measured and recorded the vibration accelerations of 18 observation towers (Fig. 2.)

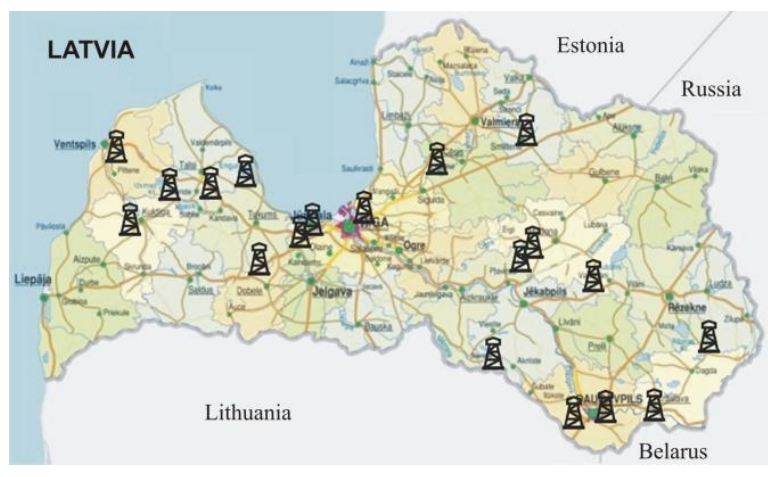

Fig. 2. Location of observation towers in Latvia.

There were used five 3-axis light-weight (55g) USB accelerometers (Model X6-1A) to record the accelerations. Devices were located on the upper platform of towers. The measurement sample rate is $160 \mathrm{~Hz}$. Each accelerometer simultaneously records vibration accelerations in three directions. The typical arrangement of accelerometers is presented in Fig. 3.

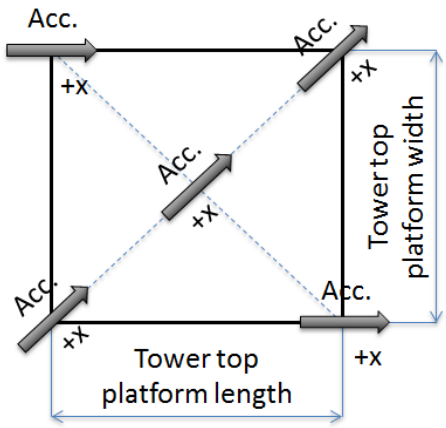

Fig. 3. Accelerometers arrangement scheme
The acceleration amplitudes were measured under the following conditions: very mild wind and no visitors on the tower, two visitors moving upstairs and afterwards downstairs the tower and free decay of vibrations. Additionally, there were measured the geometry of structures and weather conditions during the experiments.

\section{B. Processing technique of experimental data}

The structural dynamic behavior denotes the modal parameters of structure (natural frequencies, damping ratios and mode shapes). The field of research so called "modal analysis" is dealing with identification of those parameters.

The branch of modal analysis is operational modal analysis that aims to determine the dynamic character istics of structure under operational conditions.

Excitation force of two person movement along tower's height is weak compared to observation tower's self-weight and stiffness therefore peaks in the output spectrum will be responses in the structural modes.

There was performed spectral analysis using software package ME'scopeVES to determine the exited frequency content of simultaneously recorded time traces of observation tower's top platform accelerations.

There were obtained the autocorrelation functions (1) of the time traces that show how the mean power in a signal is distributed over frequency. It is also a very handy tool to detect the harmonic signals buried in the noise [8].

$$
G_{A A}(f)=A(f) \cdot A^{*}(f),
$$

where $A(f)$ is the Fourier transform of the time trace $\mathrm{a}(\mathrm{t})$ defined as:

$$
A(f)=\int_{-\infty}^{\infty} a(t) e^{-i f t} d t
$$

The "*" indicates the complex conjugate and:

$$
e^{i f t}=\cos (f t)+i \sin (f t),
$$

where $i$ is a unity imaginary number.

To reduce the leakage effects due to non-periodicity of the time signal records the "Hanning window" was applied to each sampling window before the FFT (Fast Fourier Transform) was applied. In the ME'scopeVES the modal parameters are extracted from the cross channel measurement functions using FRF-based curve fitting methods. The DeConvolution window was applied to remove the "second half" of the time domain correlation function associated with the measurement.

To check the reliability of obtained natural frequencies there was used the stabilization diagram that subsequently assumes an increasing number of poles. 


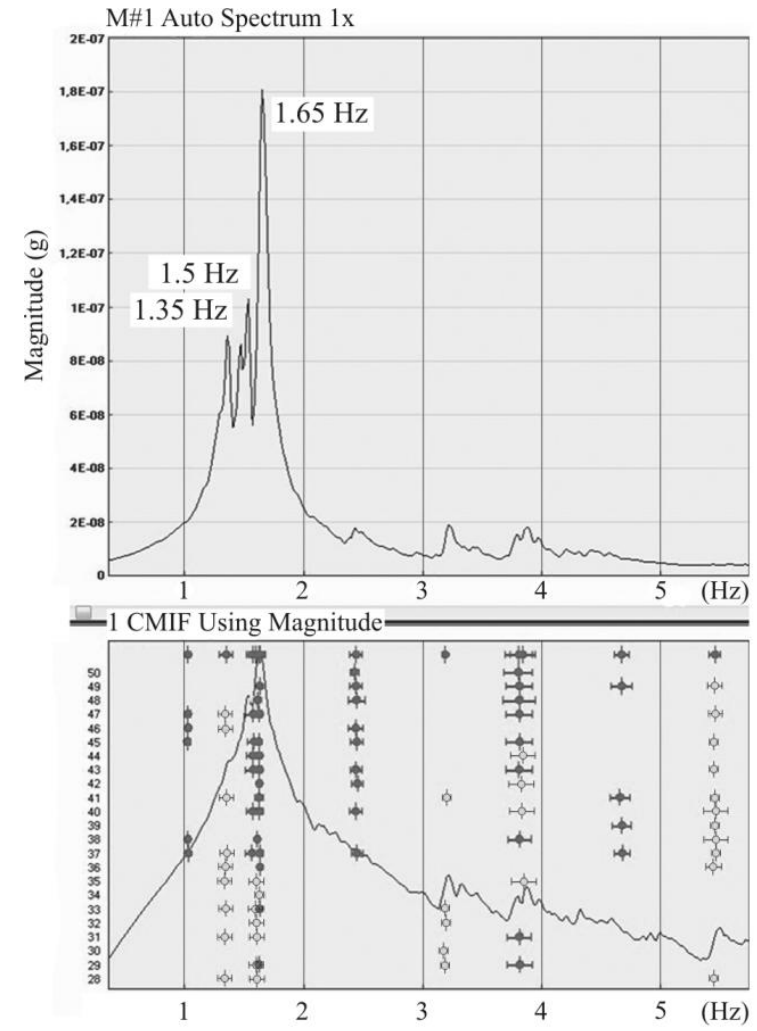

Fig. 4. Response spectrum and stabilization diagram of Ligatne tower due to 2 persons ascending
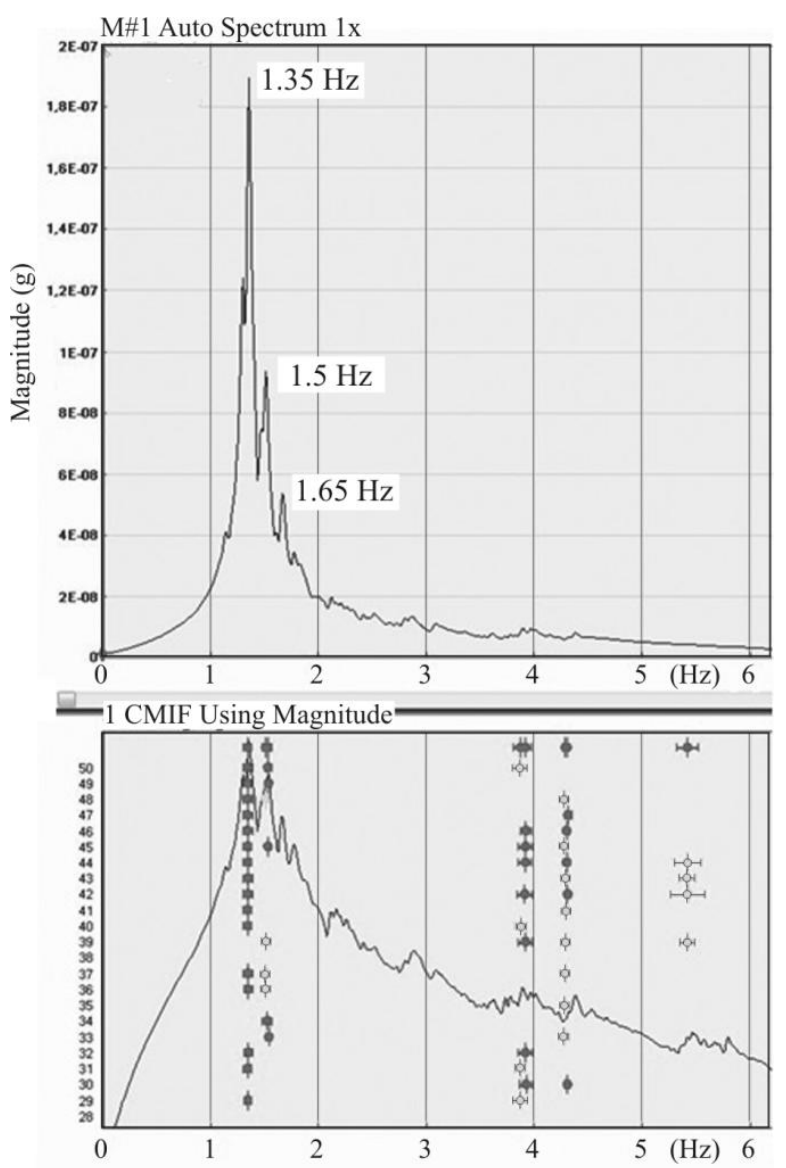

Fig. 5. Response spectrum and stabilization diagram of Ligatne tower due to 2 persons descending
The physical poles (exited frequencies) always appear as "stable poles" consequently the unrealistic poles are filtered out. Examples of obtained auto spectrum and stabilization diagrams presented in Fig. 4 and 5.

Damping ratios of the towers were obtained from free decay time histories using formula (4) [9]:

$$
\xi=\frac{1}{2 \pi n} \ln \frac{a_{0}}{a_{n}}
$$

where,

$n$ - number of relevant periods in time history;

$a_{0}$ - max amplitude;

$a_{n}$ - min amplitude.

\section{Theoretical Background}

Slender sightseeing towers are the line - like structure and for the purpose of response analysis it was modeled as the cantilever with uniformly distributed mass along the height. The foundation stiffness was not taken into account. The observation tower's loading scheme for analytical investigation of different parameters (mass, stiffness and tower height) influence on the structures dynamic response is presented in Fig. 6.

$$
\begin{gathered}
\mathrm{F}(\mathrm{t})=\mathrm{F}_{0} \sin (\Omega \mathrm{t}) \\
\mathrm{F}_{0}=2 \mathrm{G}^{1} \\
\Omega=2 \pi \mathrm{f}_{1} \\
\mathrm{G}-\text { weight of the } \\
\text { mean person, } \mathrm{N} \\
\lambda^{1}-\text { DLF of } 1^{\text {st }} \\
\quad \text { walking harmonic } \\
\mathrm{f}_{1}-\text { walking } \\
\text { frequency, Hz } \\
\text { tा/ा/7/7 } \quad
\end{gathered}
$$

Fig. 6. Calculation scheme

According to generally accepted design processes for low frequency structures it is convenient to consider the maximum level of the resonant response that can be induced by person under repeated footfall. It was previously found that tower would not reach "the steady state vibration" due to inconsistent periodicity of applied loading [10]. Thus for the sensitivity analysis purpose the load is applied in the horizontal direction with magnitude of two persons' typical first walking harmonic (longitudinal direction) at cantilever tip. The weight of one person is assumed $740 \mathrm{~N}$ and dynamic load factor (DLF) is assumed 0.12.

The sensitivity analysis was performed in the following parameter range:

Height of the tower: $20 \mathrm{~m} \ldots 40 \mathrm{~m}$;

Self-weight of the tower: $4 \mathrm{kN} / \mathrm{m} \ldots 1500 \mathrm{kN} / \mathrm{m}$;

Stiffness of the structure (EI):

$1.4 \cdot 10^{9} \mathrm{Nm}^{2} \ldots 1.610^{10} \mathrm{Nm}^{2}$.

The reference tower parameters are following:

Height of the tower: $\mathrm{L}_{\mathrm{av}}=30 \mathrm{~m}$;

Self-weight of the tower: $\mathrm{m}_{\mathrm{av}}=9.5 \mathrm{kN} / \mathrm{m}$

Stiffness of the structure: $\mathrm{EI}_{\mathrm{av}}=9.04 \cdot 10^{9} \mathrm{Nm}^{2}$; 
Damping ratio: $\xi=2.5 \%$.

In calculations it was considered that 4 repeated footfalls in a row coincide with the fundamental frequency of the structure.

The methodology for obtaining the analytical solution (displacements and accelerations) of equation of motion (5) is taken from [10].

$$
\begin{aligned}
& \frac{\delta^{2}}{\delta y^{2}}\left[E I(y) \frac{\delta^{2} x}{\delta y^{2}}\right]+m(y) \frac{\delta^{2} x}{\delta t^{2}}+ \\
& +c(y) \frac{\delta x}{\delta t}=G \lambda^{1} \sin (\Omega t),
\end{aligned}
$$

where,

$$
\begin{aligned}
& E I \text { - stiffness; } \\
& x \text {-displacement; } \\
& c \text {-damping; } \\
& m \text {-mass. }
\end{aligned}
$$

\section{RESULTS AND DISCUSSION}

There were experimentally measured and recorded data of 18 observation tower's top platform vibration acceleration under a mild wind and two persons movement along the tower's height to obtain the exited natural frequencies, damping ratios and acceleration amplitudes for the light-weight lattice towers made of different materials.

There were some examples of mixed structures e.g. timber structure (columns, beams, and cladding) with a steel rod lateral resisting system. Mostly observation towers can be divided in timber $(70 \%$ of the inspected towers) and steel structures. The slope of the observation towers' stairs was in the range of $30^{\circ}$ to $70^{\circ}$ but most of the observation towers' slop of the stairs was around $45^{\circ}$. Although the most of observation towers are less than ten years old their technical condition widely varies. Only the timber towers less than five years old with a treated timber are in good technical condition.

The recorded time histories and corresponding frequency spectrums with stabilisation diagrams of the observation tower in Ligatne are presented in Fig 7. The recorded peak accelerations under mild wind conditions are about 20 times less than from two person movement upstairs and downstairs. Most of this tower's height was sheltered by surrounding trees. In this case response spectra show that ascending and descending excite the same frequencies. In ascending case higher magnitude has the fundamental frequency of the tower $(1.35 \mathrm{~Hz})$ but in descending case higher magnitude has higher frequency $(1.65 \mathrm{~Hz})$.

Tower response to wind loading
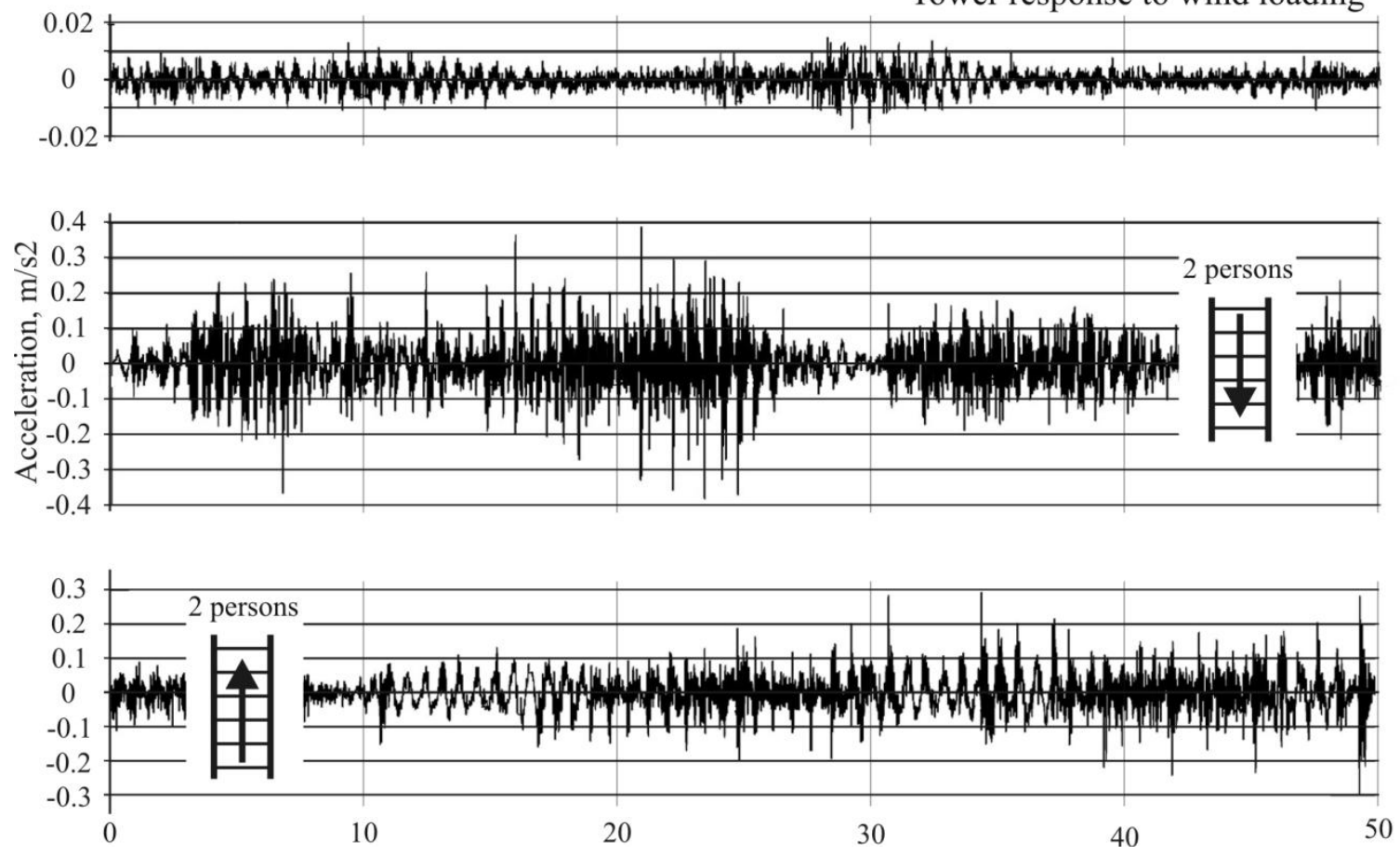

Fig. 7. Acceleration time history of observation tower in Ligatne

Table 1 presents the three main exited natural frequencies of observation towers and maximum accelerations observed due to two persons movement up and down the tower stair as well as presented damping ratios in such were obtained.

The Table 1 excludes the inspected towers that were in unsatisfactory technical condition.
The lowest exited frequencies of human movement are generally the fundamental frequencies of the observation towers. To recognize it, there was analysed frequency spectrum of each tower obtained from ambient response data where as an input force was considered the wind loading. 
TABLE 1.

OBSERVATION TOWER DYNAMIC RESPONSE TO HUMAN INDUCED LOADING

\begin{tabular}{|c|c|c|c|c|c|c|c|c|c|}
\hline \multirow{2}{*}{$\begin{array}{l}\text { Tower name and height of } \\
\text { the top platform above the } \\
\text { ground level }\end{array}$} & \multirow{2}{*}{$\begin{array}{c}\text { Structural } \\
\text { material } \\
\text { Steel }\end{array}$} & \multicolumn{6}{|c|}{ Exited frequencies of two persons movement, $\mathrm{Hz}$} & \multirow{2}{*}{$\begin{array}{r}\mathrm{A}_{\max }, \\
\mathrm{m} / \mathrm{s}^{2}\end{array}$} & \multirow{2}{*}{$\begin{array}{r}x, \% \\
0.8\end{array}$} \\
\hline & & 2.6 & 2.8 & - & 2.6 & 2.8 & - & & \\
\hline Kalsnava tower $(25 \mathrm{~m})$ & Steel & 1.7 & - & - & 1.6 & 1.7 & 2.2 & 0.33 & 1.7 \\
\hline Jurmala tower (34m) & Steel & 0.75 & 0.8 & 1.15 & 0.8 & 3.3 & - & 0.35 & 2.3 \\
\hline Eglu kalns $(26.5 \mathrm{~m})$ & Timber & 1.3 & 4.2 & - & 1.3 & 2.5 & 4.2 & 0.3 & 4 \\
\hline Priedaine (32m) & Timber & 1.2 & 2 & 3.1 & 1.1 & 2 & 2.2 & 0.26 & - \\
\hline Kamparkalns (26.5m) & Timber & 1.35 & 1.45 & - & 1.45 & 2.85 & - & 0.3 & 3.1 \\
\hline Udru kalns (26.5m) & Timber & 1.35 & 2.6 & - & 1.35 & 1.55 & 2.6 & 0.25 & 3.85 \\
\hline Ventspils tower $(12 \mathrm{~m})$ & Steel & \multicolumn{7}{|c|}{ Excitement is negligible; fundamental frequency is $3.4 \mathrm{~Hz}$} & - \\
\hline Kuldiga tower (16.3m) & Mixed & 0.8 & $1.1,1.2$ & 2.6 & 0.8 & 1.2 & 2.6 & 0.26 & - \\
\hline Lielais liepu tower $(34 \mathrm{~m})$ & Timber & 1.1 & 1.3 & 2.1 & 1.1 & 1.5 & 4.7 & 0.13 & - \\
\hline Ligatne tower $(22 \mathrm{~m})$ & Timber & 1.35 & 1.5 & 1.65 & 1.35 & 1.5 & 1.65 & 0.25 & 5.4 \\
\hline Lozmeteju tower (28.5) & Timber & 1 & 1.1 & 2.2 & 1 & 1.1 & - & 0.3 & - \\
\hline
\end{tabular}

All fundamental frequencies of the inspected towers are in the typical human walking range as given in the [10]. It is noticed that generally during the stair ascend case with highest acceleration amplitude exited the lowest natural frequency but in descending case there could be different dominant natural frequency. It corresponds well with the observations during the experiment that visitors move downstairs faster than upstairs. The differences in the exited natural frequencies of the towers with very similar structure and the same fundamental frequency due to human movement (Kamparkals tower and Udru kalns tower) indicate the stochastic nature of human dynamic loading.

Although the inspected towers varies in the structural arrangements and materials the maximum response level (acceleration amplitude) of two persons movement are close to $0.3 \mathrm{~m} / \mathrm{s}^{2}$. The exception are two steel towers (Krustkalns and Jurmala) that are considerably lighter and have higher acceleration amplitudes and tower in Ventspils that is very short with no visible effect from human movement.

To analyse the different parameter (tower's selfweight, height and stiffness (EI)) influence theoretically on the dynamic response level due to two persons movement was performed the sensitivity analysis for the range of parameters as given in the previous section of the paper. The Fig. 8 presents tower tip displacement amplitude changes if one of the considered parameters is changed but others are fixed. The Fig. 9 shows acceleration amplitude changes in a similar manner.
The perception of vibration depends on vibration frequency and the acceleration amplitudes are directly related to pedestrian comfort [11]. Therefore there is a specific interest in amplitude values of accelerations.

Results of the sensitivity analysis reveal that a change in tower stiffness does not influence the acceleration amplitudes. The most important parameter is mass of the structure that does not influence the displacement amplitudes but significantly influences the acceleration amplitudes.

Basically, stiffer structure has higher frequency however displacements are smaller and as a result there is no significant change in the acceleration amplitude. This well correspond with the experimental results where the acceleration levels are approximately the same for towers with similar self-weight.

In reality there is impossible the situation when changes of the stiffness or height of tower would not influence the self-weight of structure. Nevertheless the sensitivity analysis confirms that lighter towers made of stronger materials such as steel compared to timber ones will be more prone to human movement induced vibrations and could reach higher acceleration values. This corresponds well with the experimental results in the Table 1.

Experimentally determined peak acceleration of Lielais liepu kalns tower $A_{\max }=0.13 \mathrm{~m} / \mathrm{s}^{2}$ (Table 1) is considerably smaller than other timber towers have, although the fundamental frequency is quite low $(1.1 \mathrm{~Hz})$. 


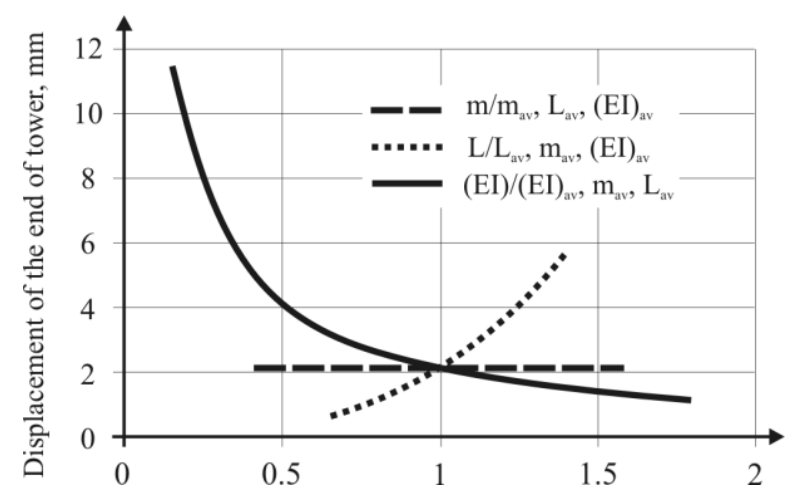

Fig. 8. Displacement amplitude of tower tip due to geometrical parameter change

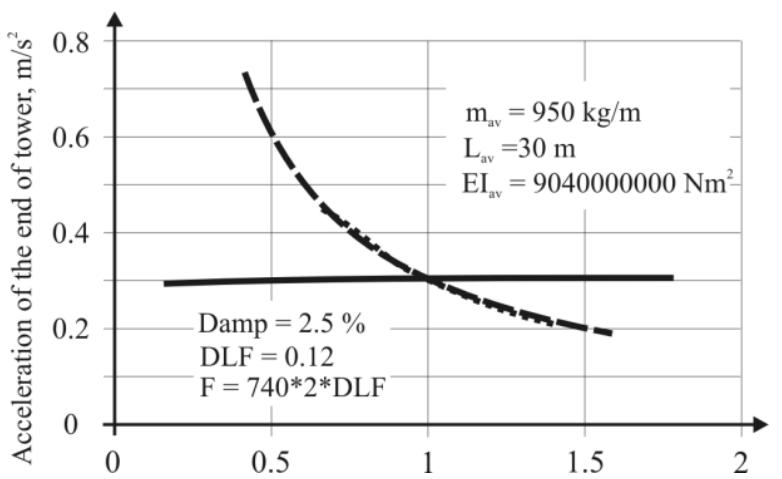

Fig.9. Acceleration amplitude of tower tip due to geometrical parameter change

The structure of this particular tower has additional structural elements that increases the tower selfweight but do not increase significantly the stiffness of the structure and the tower visitors did not have any discomfort feeling compared to other towers with peak acceleration more than $0.25 \mathrm{~m} / \mathrm{s}^{2}$. This corresponds well with the carried out theoretical sensitivity analysis.

\section{CONCLUSIONS}

The experimental data presented in this paper are based on measurements of 12 light - weight lattice observation towers' (with different structural assembly and used materials) responses (acceleration amplitudes) to human induced dynamic loading. In theoretical part of the paper particular attention is paid to find the parameters of the structure that mostly influence the dynamic response level (displacements and accelerations) to this loading. The main conclusions from the study can be summarized as follows:

1. Observation towers are sensitive to the human induced loads. Human movement along the tower height induces vibration with frequencies that are natural frequencies of the structure.

2. The experimental results reveal the different natural frequencies with different magnitude redistribution of towers with a similar geometry and same fundamental frequency were exited. This indicates the stochastic nature of human induced loading. In all cases there were exited several natural frequencies with comparable magnitudes. Generally, ascending the tower stairs excites the lowest natural frequencies of the structure with highest acceleration amplitudes. When descending the tower stairs the acceleration magnitude distribution over frequencies differs from the ascending case. Then the higher amplitudes have exited frequencies closer to $2 \mathrm{~Hz}$. This correlates with observation that tower visitors descend the tower stairs at higher speed than ascend.

3 . The damping ratios of timber observation towers are roughly twice $(x \approx 4 \%)$ of steel ones.

4. The parameter that mostly influences the tower acceleration amplitudes due to human movement induced loads are the self-weight of the structure.

5. The good correlation between the experimental results and theoretical analysis predicting the acceleration amplitudes induced by human movement indicates that the made assumption of considered 4 repeated footfalls in a row coincides with the fundamental frequency of the structure is adequate.

\section{ACKNOWLEDGMENTS}

This work has been supported by the European Social Fund within the project "Support for the implementation of doctoral studies at Riga Technical University".

\section{REFERENCES}

[1] L. Gaile. and I. Radinsh, Eccentric lattice tower response to human induced dynamic loads. Proceedings of 19th International Congress on Sound and Vibration, July 8-12, 2012, Vilnius, Lithuania, CD-ROM, pp. 560-567, 2012.

[2] E. T. Ingolfsson and C.T. Georgakis, "A stochastic load model for pedestrian - induced lateral forces on footbridges", Engineering Structures, 33, pp. 3454-3470, 2011.

[3] F. Venuti and L. Bruno, "Crowd - structure interaction in lively footbridges under synchronous lateral excitation: A literature review", Physics of Life Reviews, 6, pp. 176-206, 2009.

[4] S. Zivanovic, A. Pavic and P. Reynolds "Vibration Serviceability of Footbridges under Human - Induced Exitation: A Literature Review", Journal of Sound and Vibration, 279 (1-2), pp. 1-74, 2004.

[5] S. Zivanovic and A. Pavic, "Probabilistic assessment of human response to footbridge vibration", Journal of Low Frequency Noise, Vibration and Active Control, Vol. 28(4), pp. 255-268, 2009.

[6] C. Butz, M. Feldmann and et.al., "Advanced load models for synchronous pedestrian excitation and optimised design guidelines for steel footbridges," European Commission, Research Fund for Coal and Steel, European Communities, Tech. Rep., 2008.

[7] T. Kretz, A. Grunebohm, and et. al., "Upstairs Walking Speed Distributions on a Long Stair-way", Safety Science, 46, pp. 72-78, 2008

[8] W. Heylen, S. Lammens and P. Sas, Modal analysis theory and testing. Leuven: Katholieke Universiteit Leuven, 2007.

[9] H. A. Büchholdt and S. E. M. Nejad, Structural Dynamics for Engineers. ICE Publishing: UK, 2011.

[10] L. Gaile. and I. Radinsh, Lattice tower dynamic performance under human induced loading. Proceedings of 11th International Conference on Recent Advances in Structural Dynamics, July 1-3, 2013, Pizza, Italy, accepted for publishing, 2012.

[11] M. J. Griffin, Handbook of Human Vibration. Elsevier Ltd., 2004. 